\title{
Effects of Thermal Treatment on the Co- rolled U-Mo Fuel Foils
}

\section{Materials Research Society}

Jan-Fong Jue, Dennis D. Keiser, Jr., Tammy L. Trowbridge, Cynthia R. Breckenridge, Brady L. Mackowiak, Glenn A. Moore, Barry H. Rabin, Mitchell K. Meyer

The INL is a

U.S. Department of Energy

National Laboratory

operated by

Battelle Energy Alliance

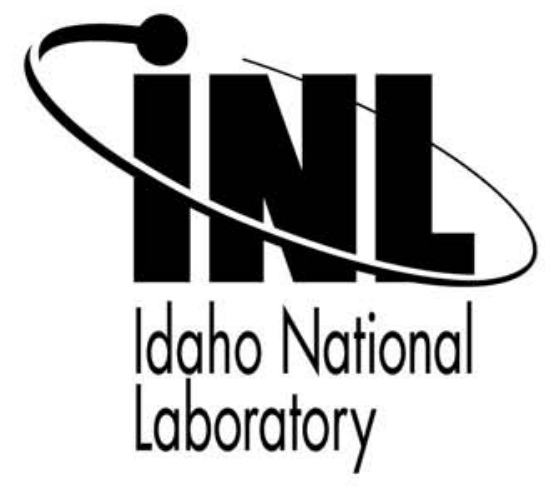

November 2014

This is a preprint of a paper intended for publication in a journal or proceedings. Since changes may be made before publication, this preprint should not be cited or reproduced without permission of the author. This document was prepared as an account of work sponsored by an agency of the United States Government. Neither the United States Government nor any agency thereof, or any of their employees, makes any warranty, expressed or implied, or assumes any legal liability or responsibility for any third party's use, or the results of such use, of any information, apparatus, product or process disclosed in this report, or represents that its use by such third party would not infringe privately owned rights. The views expressed in this paper are not necessarily those of the United States Government or the sponsoring agency. 


\title{
Effects of Thermal Treatment on the Co-rolled U-Mo Fuel Foils
}

Jan-Fong Jue ${ }^{1}$, Dennis D. Keiser, Jr. ${ }^{1}$, Tammy L. Trowbridge ${ }^{1}$, Cynthia R. Breckenridge ${ }^{1}$, Brady L. Mackowiak ${ }^{1}$, Glenn A. Moore ${ }^{1}$, Barry H. Rabin ${ }^{1}$, and Mitchell K. Meyer ${ }^{1}$

${ }^{1}$ Idaho National Laboratory, 2525 Fremont Avenue, Idaho Falls, ID 83415, U.S.A.

\begin{abstract}
A monolithic fuel design based on U-Mo alloy has been selected as the fuel type for conversion of United States' high-performance research reactors (USHPRRs) from highly enriched uranium (HEU) to low-enriched uranium (LEU). In this fuel design, a thin layer of zirconium is used to eliminate the direct interaction between the U-Mo fuel meat and the aluminum-alloy cladding during irradiation. The co-rolling process used to bond the $\mathrm{Zr}$ barrier layer to the U-Mo foil during fabrication alters the microstructure of both the U-10Mo fuel meat and the $\mathrm{U}-\mathrm{Mo} / \mathrm{Zr}$ interface. This work studied the effects of post-rolling annealing treatment on the microstructure of the co-rolled U-Mo fuel meat and the U-Mo/Zr interaction layer. The U$\mathrm{Mo} / \mathrm{Zr}$ interaction-layer thickness increased with the annealing temperature with an Arrhenius constant for growth of $184 \mathrm{~kJ} / \mathrm{mole}$, consistent with a previous diffusion-couple study. The phases in the U-Mo/Zr interaction layer produced by co-rolling, however, differ from those reported in the previous diffusion-couple study.
\end{abstract}

\section{INTRODUCTION}

A U-Mo-based dispersion fuel type is the current nuclear fuel for most research and test reactors. Most of the existing literature on U-Mo nuclear fuels is on dispersion fuel type, References 1-3 give some examples. However, low fuel density and unstable behavior at high fission densities make dispersion fuel unsuitable for the conversion of remaining US high performance reactors, which utilize highly enriched uranium. Extensive development efforts to qualify an advanced monolithic fuel type have been carried out under the USHPRR program. To date, almost 100 monolithic fuel plates, ranging from 4-40 inches in length, have been irradiated in the Advanced Test Reactor (ATR) at Idaho National Laboratory (INL). Most of the fuel-performance data obtained indicate that the current U-Mo monolithic fuel design exhibits adequate irradiation performance. Recently, post-irradiation examination results suggested that the microstructure of U-Mo fuel meat and the interface between U-Mo and zirconium can be critical for fuel performance at high burnup. Specifically, Mo segregation (chemical banding) was observed in U-Mo fuel meat after irradiation, and large bubbles tend to precipitate out earlier in the areas with lower Mo concentration. The focus of this study is on the effect of annealing treatments on the homogeneity of Mo in U-Mo fuel meat and its impacts on the U$\mathrm{Mo} / \mathrm{Zr}$ interaction layer.

\section{EXPERIMENT}

Source materials of depleted uranium and molybdenum were arc-melted and drop-cast into a graphite mold to yield a coupon. Some of the coupons were homogenized at $1000^{\circ} \mathrm{C}$ for 2 hours 
before the rolling process. The coupon was then placed in a low-carbon-steel can with a 0.010 -in. zirconium foil on both the top and bottom of it. The rolling assembly is heated to $650^{\circ} \mathrm{C}$ in a box furnace before being hot-rolled to the targeted thickness (a 74\% reduction in thickness). After hot-rolling, foils were annealed at $650^{\circ} \mathrm{C}$ for 45 minutes before being removed from the can and cold-rolled to the final thickness (another 50\% reduction in thickness). The final total thickness of the fuel foils is approximately $300 \mu \mathrm{m}$ (including a $25-\mu \mathrm{m}$-thick $\mathrm{Zr}$ layer on each side of the fuel foil). Post-cold-rolling annealing treatments were performed for one hour at $650^{\circ} \mathrm{C}, 750^{\circ} \mathrm{C}$, and $850^{\circ} \mathrm{C}$, respectively.

Microscopy samples were cut from the fuel foil using a Buehler high-speed saw in a radiological fume hood. Samples were mounted in an epoxy mount. The samples were first ground using increasingly fine sandpaper grit (down to 1200-grit). After grinding, the epoxy-mounted samples were finished with 3 - and 1- $\mu \mathrm{m}$ diamond suspensions to expose the cross-section. Before samples could be observed under scanning electron microscope, they were sputter coated with a thin layer of gold. Scanning electron microscopy (SEM) was performed using a JEOL 7000F field emission scanning electron microscope equipped with Oxford energydispersive X-ray spectroscopy (EDS) and wavelength-dispersive X-ray spectroscopy (WDS) systems. Both secondary-electron (SE) and backscattered-electron (BSE) images were taken using a $20 \mathrm{kV}$ accelerating voltage and a $10 \mathrm{~mm}$ working distance. Chemical-composition information was obtained using Oxford INCA EDS semi-quantitative point analysis and EDS/WDS mapping functions.

\section{RESULTS AND DISCUSSION}

Molybdenum segregation is commonly observed in the as-cast U-Mo coupons. The Mo segregation remained in the fuel foils after the rolling process, as is evidenced by the existence of chemical banding in the U-Mo fuel meat (shown in Figure 1). Mo concentration as high as 12 weight $\%$ was measured in the darker-colored bands. The light-colored regions exhibit Mo concentration as low as 7 weight \%. The Mo homogeneity improved with increasing post-rolling annealing temperature. Figure 2 shows EDS plots of Mo concentration in the U-Mo fuel meat subjected to a post-rolling annealing treatment for 1 hour at $650^{\circ} \mathrm{C}$ or $850^{\circ} \mathrm{C}$. The average Mo concentrations are $9.92 \pm 0.78 \mathrm{wt} \%$ and $9.93 \pm 0.4 \mathrm{wt} \%$ for fuel foils annealed at $650^{\circ} \mathrm{C}$ and $850^{\circ} \mathrm{C}$, respectively. The range of Mo concentration in the U-Mo fuel meat narrowed from 7-12 $\mathrm{wt} \%$ in the fuel foil annealed at $650^{\circ} \mathrm{C}$ to $9-11 \mathrm{wt} \%$ in the fuel foil annealed at $850^{\circ} \mathrm{C}$.

The interaction layer between U-Mo fuel meat and $\mathrm{Zr}$ diffusion barrier was characterized by scanning electron microscopy. Figure 3 shows an SEM micrograph of a visible interaction layer (arrowed) between $\mathrm{U}-\mathrm{Mo}$ and $\mathrm{Zr}$ in a fuel foil subjected to a post-rolling annealing treatment at $650^{\circ} \mathrm{C}$ for 1 hour. This interaction layer actually contains several sub-layers. The sub-layers are similar to what was typically observed in monolithic fuel plates [4,5]. Based on previous studies, the smooth layer closest to $\mathrm{Zr}$ is a $\mathrm{UZr}_{2}$-bearing sub-layer, followed by dark $\mathrm{Mo}_{2} \mathrm{Zr}$ precipitates (becoming a sub-layer in some locations). A low-Mo (usually 5 weight $\%$ Mo or lower) sublayer, slightly brighter in contrast, was also observed between the $\mathrm{UZr}_{2}$-bearing sub-layer and the $\mathrm{U}-\mathrm{Mo}$ fuel meat. The total thickness of the interaction layer (including $\mathrm{UZr}_{2}$-bearing, $\mathrm{Mo}_{2} \mathrm{Zr}$ bearing and Mo depleted sub-layers) is measured to be $3.2 \pm 0.5 \mu \mathrm{m}$ (an average of 10 different locations). The $\mathrm{U}-\mathrm{Mo} / \mathrm{Zr}$ interaction layer grew thicker as the post-rolling annealing temperature increased. The SEM micrograph in Figure 4 shows the interfacial area of a fuel foil subjected to 
a post-rolling annealing treatment at $850^{\circ} \mathrm{C}$. It was also observed that the $\mathrm{UZr}_{2}$-bearing sub-layer became discontinuous toward the pure $\mathrm{Zr}$ region.
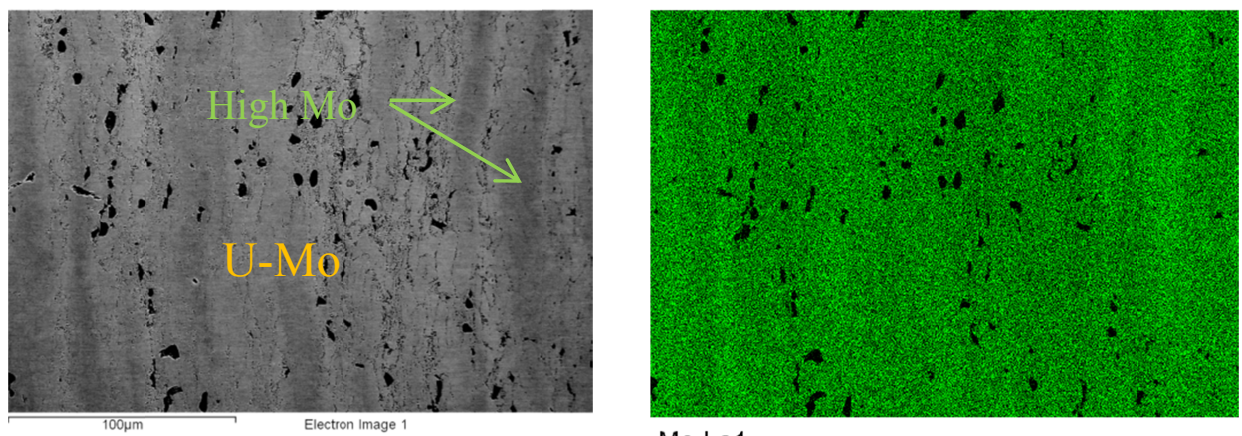

Mo La1

Figure 1. SEM micrograph showing the chemical banding in the U-Mo fuel foil subjected to a post-cold-rolling annealing treatment at $650^{\circ} \mathrm{C} / 1 \mathrm{hr}$. Black precipitates are carbide/oxides [5].

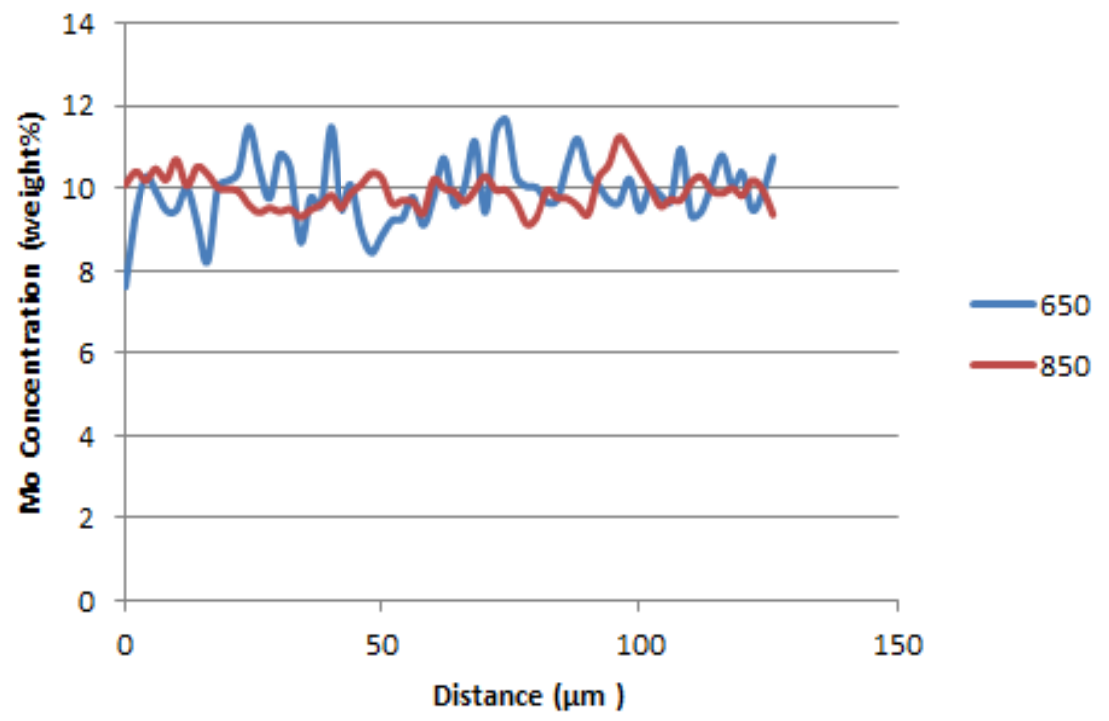

Figure 2. Mo concentration profiles (perpendicular to the U-Mo/Zr interface) in U-Mo fuel foils subjected to post-cold-rolling annealing treatments for 1 hour at $650^{\circ} \mathrm{C}$ (blue curve) and $850^{\circ} \mathrm{C}$ (red curve). 


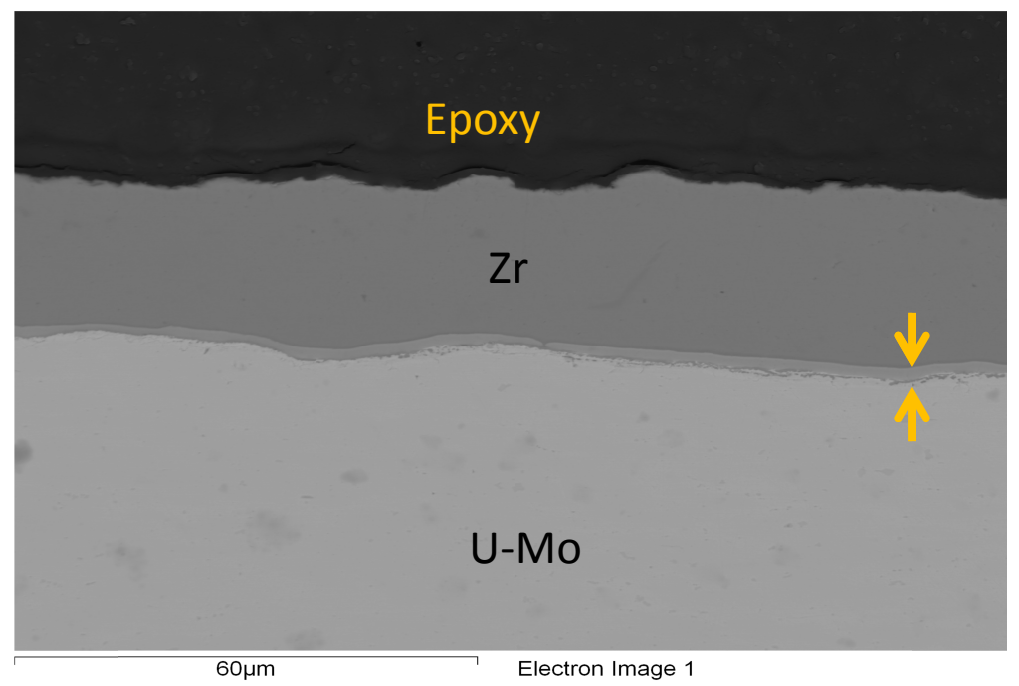

Figure 3. An SEM micrograph of the U-Mo/Zr interface in a fuel foil subjected to a post-coldrolling annealing treatment at $650^{\circ} \mathrm{C}$ for 1 hour.

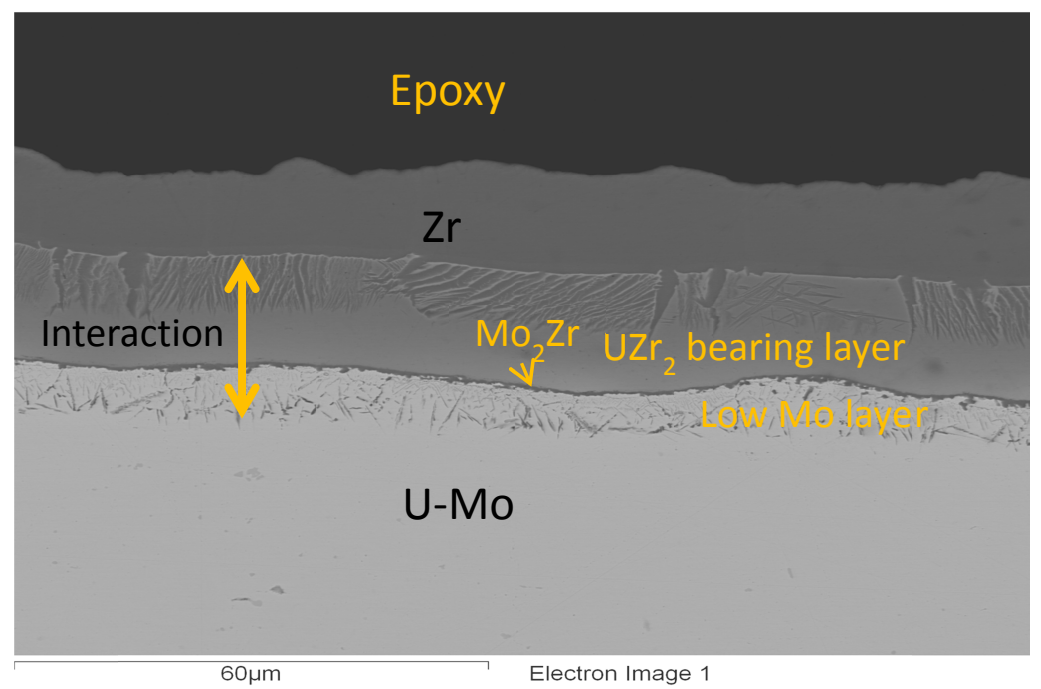

Figure 4. An SEM micrograph from a fuel foil subjected to a post-cold-rolling annealing treatment of $850^{\circ} \mathrm{C}$ for 1 hour.

The U-Mo/Zr interaction-layer thickness for different annealing-treatment temperature has been measured and is shown in Table 1 . The growth rate for a specific temperature can be calculated using the relationship $\mathrm{K}=(\text { increase in IL thickness) })^{2} / 2 \mathrm{t}$, where $\mathrm{t}$ is time (in seconds) and $\mathrm{K}$ is the rate constant (in $\mathrm{m}^{2} / \mathrm{sec}$ ). Because the $\mathrm{U}-\mathrm{Mo} / \mathrm{Zr}$ interaction layer has become very thin and discontinuous after cold rolling, it is assumed that the initial interaction-layer thickness before the post-rolling annealing treatment is negligible. The calculated growth rate of the interaction layer, $\mathrm{K}$, is given in Table 1 . The activation energy of the inter-diffusion can be determined using equation

$$
K=K_{0} \exp (-Q / R T)
$$


where $K_{o}$ is a constant, $R$ is the gas constant and $T$ is annealing temperature (in Kelvin). By plotting $\log (\mathrm{K})$ versus $(1 / \mathrm{T})$, the activation energy for the $\mathrm{U}-\mathrm{Mo} / \mathrm{Zr}$ interaction layer growth is determined to be $184 \mathrm{~kJ} / \mathrm{mol}$ and $K_{o}$ is calculated to be $3.76 \times 10^{-5} \mathrm{~m}^{2} / \mathrm{sec}$. This activation energy is very close the activation energy obtained by Huang et al. $(183.83 \mathrm{~kJ} / \mathrm{mol})$ using U-Mo and $\mathrm{Zr}$ diffusion couples [6]. However, one significant difference exists between the previous diffusioncouple study and this work: the phases in the $\mathrm{U}-\mathrm{Mo} / \mathrm{Zr}$ interaction layer are different. Instead of a $\beta$-zirconium layer, as reported in the previous diffusion-couple study [6], a $\mathrm{UZr}_{2}$-bearing and a low-Mo sub-layer were observed in this work and an earlier study [4]. The reason for the difference is not clear at this time. Impurities, such as oxygen and iron, on the U-Mo/Zr interface and the cooling rate after annealing treatment can impact the phases obtained in the interfacial area.

Table 1. U-Mo/Zr interaction layer thickness and growth rate of fuel foils subjected to a postrolling annealing treatment at different temperatures.

\begin{tabular}{|l|l|l|l|}
\hline & $650^{\circ} \mathrm{C}$ & $750^{\circ} \mathrm{C}$ & $850^{\circ} \mathrm{C}$ \\
\hline IL thickness $(\mu \mathrm{m})$ & $3.2 \pm 0.5$ & $11.1 \pm 2.1$ & $27.1 \pm 0.9$ \\
\hline $\mathrm{K}\left(\mathrm{m}^{2} / \mathrm{sec}\right)$ & $1.42 \times 10^{-15}$ & $1.71 \times 10^{-14}$ & $1.02 \times 10^{-13}$ \\
\hline
\end{tabular}

Even though the annealing treatment enhances Mo homogeneity in U-Mo fuel foil, but also significantly increases the interaction between $\mathrm{U}-\mathrm{Mo}$ and zirconium at 750 and $850^{\circ} \mathrm{C}$. Too thick an interaction layer can negatively impact the fuel performance. Some U-Mo coupons were subjected to homogenization treatment at $1000^{\circ} \mathrm{C}$ for 2 hour in order to eliminate or minimize the segregation of Mo in the resulting fuel foils. Identical rolling and annealing procedures were carried out on the fuel foils utilizing U-Mo coupons subjected to a homogenization treatment at $1000^{\circ} \mathrm{C}$ for 2 hours. The fuel foils utilizing U-Mo coupons with and without a homogenization treatment at $1000^{\circ} \mathrm{C}$ for 2 hours exhibit similar $\mathrm{U}-\mathrm{Mo} / \mathrm{Zr}$ interaction layer thickness. Based on the results of the EDS chemical analysis, as shown in Figure 5, this homogenization treatment minimized the range of Mo concentration to $9-11 \mathrm{wt} \%$ (the average Mo concentration is $9.91 \pm$ $0.15 \mathrm{wt} \%$ ) without negative impact on the interaction layer between U-Mo and zirconium.

\section{CONCLUSIONS}

Homogeneity of Mo in U-Mo fuel meat improves with increased post-rolling annealing temperature, as expected. The thickness of $\mathrm{U}-\mathrm{Mo} / \mathrm{Zr}$ interaction layer also increases with the increased temperature of the post-rolling annealing treatment. The activation energy was calculated to be $184 \mathrm{KJ} /$ mole, which is consistent with the previous diffusion-couple study. Homogenization treatment at $1000^{\circ} \mathrm{C}$ for 2 hours was performed on some as-cast coupons to minimize the Mo segregation in the resulting U-Mo fuel foils. This high-temperature treatment effectively reduced the Mo variation in U-Mo fuel foils to $9-11 \mathrm{wt} \%$ without negative impact on the interaction layer between U-Mo and zirconium. 


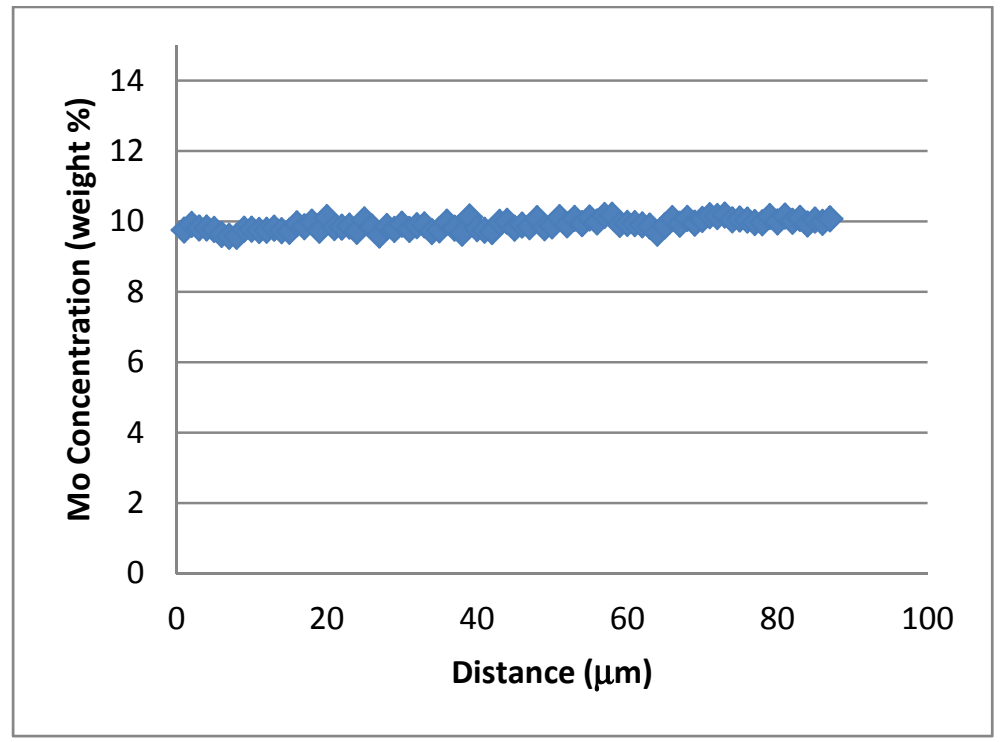

Figure 5. Mo concentration profile in U-Mo fuel foils after post-cold-rolling annealing treatment for 1 hour at $650^{\circ} \mathrm{C}$ utilizing a U-Mo coupon which is homogenized at $1000^{\circ} \mathrm{C}$ for $2 \mathrm{hrs}$. Note that no significant Mo segregation was observed in the fuel foil fabricated using a homogenized coupon.

\section{REFERENCES}

[1] M. K Meyer, G. L. Hofman, S. L. Hayes, C. R. Clark, T. C. Wiencek, J. L. Snelgrove, R. V. Strain, and K.-H. Kim, Journal of Nuclear Materials 304 221-236 (2002).

[2] D. D. Keiser, Jr., A. B. Robinson, J.-F. Jue, P. Medevedev, D. M. Wachs and M. R. Finlay, Journal of Nuclear Materials, 393 311-320 (2009).

[3] A. Leenaers, S. Van den Berghe, J. Van Eyken, E. Koonen, F. Charollais, P. Lemoine, Y. Galzavara, H. Guyon, C. Jarousse, D. Geslin, D. Wachs, D. Keiser, A. Robinson, G. Hofman, Y. S. Kim, Journal of Nuclear Materials 443 439-448 (2013).

[4] E. Perez, B. Yao, D. D. Keiser, Jr., and Y. H. Sohn, Journal of Nuclear Materials 402 8-14 (2010).

[5] Jan-Fong Jue, Dennis D. Keiser, Jr., Cynthia R. Breckenridge, Glenn A. Moore, and Mitchell K. Meyer, Journal of Nuclear Materials 448 250-258 (2014).

[6] K. Huang, Y. Park, D. D. Keiser, Jr., and Y. H. Sohn, Journal of Phase Equilibria and Diffusion 33 443-449 (2012). 